\title{
RECENT REDAGOGICAL STRATEGIES DIRECTED TOWARDS THE MAINTENANCE OF NATIONAL IDENTITY
}

\author{
Darejan Tvaltvadze \\ Faculty of Humanities at IvaneJavakhishvili Tbilisi State University, Georgia \\ Irina Gvelesiani \\ Faculty of Humanities at Ivane \\ Javakhishvili Tbilisi State University, Georgia
}

\begin{abstract}
Today's global processes foster the rapid internationalization and integration of educational systems of different countries. Globally-oriented strategies are spread all over Europe. They gradually "creep" into the state structures and set up new goals before the educational systems of developing countries. On the background of the ongoing internationalizing processes the question of the maintenance of national identity acquires an outstanding importance. State universities make an attempt to play a significant role in the solution of this problem.

The given paper presents the latest pedagogical strategies implemented at the Faculty of Humanities of Ivane Javakhishvili Tbilisi State University. The major emphasis is put on the involvement of two ongoing projects into the university studies ("English-Georgian Encyclopedic Dictionary", "The Georgian National Corpus") and students' participation in their further development. The given projects directly answer the demands of the modern epoch. On the one hand, they reveal western-oriented strategies via the introduction of the major concepts of today's lingva franca. On the other hand, they serve as the tool of the maintenance of the national identity via the enrichment of the Georgian language and popularization of the Georgian literary monuments or manuscript sources among the foreigners. The strategies highlighted in the paper directly answer the following demand of the Council of Europe: "The rich heritage of diverse languages and cultures in Europe is a valuable common resource to be protected and developed". Moreover, they can serve as an exemplary and useful model for those universities of developing countries, which strive towards the European integration and at the same time, facilitate the maintenance of the national identity.
\end{abstract}

Keywords: higher education; national identity; strategies; Tbilisi State University; teaching.

\section{Introduction}

According to the contemporary viewpoint: "Identity is a description or, in other words, the definition of the existence and belongingness" (Hüsamettin, Feyzullah, 2013).To belong to a national or "an ethnic group is to possess a common descent, cultural heritage, religion, language and a distinctive history and destiny and to feel a sense of collective uniqueness and solidarity" (Gill, 
2013)."Language plays an integral role in nation-building and identity formation" (Gill, 2013). Moreover, as an integral part of the national identity "language reflects what is most essential for any nation, its culture, history, customs and traditions. Language policy, in its turn, reflects any changes in a country or the world (social or political)" (Minasyan, 2014). The contemporary political, social and even lingual processes are directly influenced by the ongoing globalizing tendencies. The aspiration towards a unique unification and interconnectedness is accompanied by fostering the maintenance of multinationality and multi-ethnicity. The role of the preservation of national languages grows in this respect, because on the one hand, languages symbolize identities, while on the other hand, language loss has a negative impact on biodiversity conservation. Contemporary viewpoint directly indicates, that "there is a fundamental linkage between language and traditional knowledge (TK) related to biodiversity. Local and indigenous communities have elaborated complex classification systems for the natural world, reflecting a deep understanding of their local environment. This environmental knowledge is embedded in indigenous names, oral traditions and taxonomies, and can be lost when a community shifts to another language" (Endangered languages).

It's worth mentioning, that during the last decades the tendency towards shifting to lingva franca (the English language) has crossed all the boundaries. English has run rampant across the universe. As a result, "most of the 6000 languages spoken today are in danger, with around $50 \%$ of them facing extinction in the current century" (Castello, 2009). The given data have become a big source of concern for international organizations and authorities of different countries of the world. Even in 2001 the action plan of "UNESCO Universal Declaration of Cultural Diversity" fostered taking the appropriate measures towards:

- "safeguarding the linguistic heritage of humanity and giving support to expression, creation and dissemination in the greatest possible number of languages;

- encouraging linguistic diversity - while respecting the mother tongue - at all levels of education, wherever possible, and fostering the learning of several languages from the earliest age; and

- promoting linguistic diversity in cyberspace and encouraging universal access through the global network to all information in the public domain" (Endangered languages).

The encouragement of linguistic diversity has also been supported by the Council of Europe. The preamble of the Recommendation R (82) 18 of the Committee of Ministers of the Council of Europe directly indicates, that "the rich heritage of diverse languages and cultures in Europe is a valuable common resource to be protected and developed, and that a major educational effort is 
needed to convert that diversity from a barrier to communication into a source of mutual enrichment and understanding" (Council of Europe).

The given paper presents the latest pedagogical strategies implemented at the Faculty of Humanities of Ivane Javakhishvili Tbilisi State University. The major emphasis is put on the involvement of two ongoing projects into the university studies ("English-Georgian Encyclopedic Dictionary" and "Georgian National Corpus") and students' participation in their further development. The given projects directly answer the demands of the modern epoch. On the one hand, they reveal western-oriented strategies via the introduction of the major concepts of today's lingva franca. On the other hand, they serve as the tool of the maintenance of the national identity via the enrichment of the Georgian language and popularization of the Georgian literary monuments or manuscript sources among the foreigners. The paper is concluded by the discussion and assessment of the project "Georgian-Megrelian-Laz-Svan-English Dictionary", which was initiated and carried out by the professors and $\mathrm{PhD}$ student of IvaneJavakhishvili Tbilisi State University.

\section{IvaneJavakhishvili Tbilisi State University - ongoing projects and further strategies}

Georgia's contemporary social-pedagogical activities undergo a tremendous expansion via reconstructing all stages of knowledge-acquisition according to the demands of the modern epoch. Significant processes are observed on the level of higher education.

Tbilisi State University as a driving force of Georgia's educational system tries to respond to the contemporary globalizing claims and creates effective mechanisms for their fulfillment and implementation. Innovative strategies of teaching have been introduced at the Faculty of Humanities. During the recent years the portal of electronic teaching (http://e-learning.tsu.ge/) has been actively implemented in many university courses. This electronic component has been supplementing traditional methodologies of teaching and has been oriented on raising the effectiveness of knowledge acquisition. Some effects can be illustrated by the discussion of the course "The history of the Georgian literary language", which was created for the students of the direction of the Georgian philology. The portal of this course enables students to get acquainted with the syllabus, teaching materials, tasks, major topics and presentations. Moreover, it indicates resources (electronic bases and corpora) for searching for the empirical material necessary for the preparation of literary-research papers and presentations, which are necessary components of getting the scores. Among the given resources the major accent must be put on "The Georgian National Corpus” $(\boldsymbol{G N C})$ - an international partnership project, supported by the 
Volkswagen Foundation within the program "Between Europe and the OrientA Focus on Research and Higher Education in/on Central Asia and the Caucasus". The project started in 2012 under the leadership of Georgian and German scientists. Its outstanding significance can be measured according to three major parameters:

1. Scientific value - the project is focused on the development of a comprehensive corpus, "which makes the Georgian language in all its diachronic and synchronic diversity accessible to scientific investigations from various perspectives (linguistics, literary studies, history, political and social sciences, etc.)" (The Georgian National Corpus).

2. State value - "The Georgian National Corpus" is a virtual space, which facilitates the preservation of the Georgian language via:

- defending the ecology of the language;

- $\quad$ planning a progressive lingual policy;

- normalizing and standardizing the state language;

- adapting the Georgian language to the platforms of e-learning, etc.

3. International significance - the value of "The Georgian National Corpus" is raised by the fact, that it presents the literary history of Georgian, which has been written with "three different scripts in the course of time: Asomtavruli, the Old Georgian majuscule script (ca. 5th-10th cc.), Nusxa-Xucuri, the minuscule script used in manuscripts of ecclesiastical content (ca. 9th-19th cc.), and Mxedruli, the minuscule cursive used since the Middle Ages until the present day" (Gippert \& Tandashvili, 2012). Such diachronic study of the state language and digitalization of its written monuments or manuscripts serve as a useful tool for the popularization of Georgia's state language among foreigners. The number of foreign Kartvelologists (foreigners who are specialized in the Georgian language) increases and the number of Georgian-speaking population grows throughout the world. This fact prevents the Georgian language from the tendency of becoming an endangered language, which "faces extinction" throughout the further decades.

It has already been mentioned, that "The Georgian National Corpus" was created under the leadership of Georgian and German scientists. However, nowadays it embraces the participation of younger generation - the students of the Faculty of Humanities at Tbilisi State University. The students work in two different directions - digitalization of Georgian literary monuments and annotation of already-existed texts. The latter acquires the greatest importance, 
because annotation is the form of the enrichment of electronic data with a linguistic meta-information, which is presented on different independent levels. The most complete formis a multi-level annotation, which characterizes a word not only from the lingual point of view, but presents the data of alliteration and equivalency (with the English counterparts). The annotation of the words constituting the sentence "obsd3j6sbozgłsds" (The goat ate up the vineyard) can serve as a vivid example of these processes:

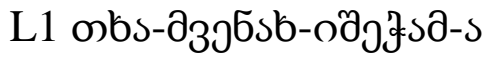
L2 txa-m venax-i še am-a
L3 goat vineyard eat
L4 NN V-tr.

L5 ERG.Sg. NOM.Sg. AOR.S3

L7 A DO PRD

L10 "The goat ate up the vineyard" (Tandashvili \& Purtskhvanidze, 2014).

Before starting participation in the creation of "The Georgian National Corpus", the students of the Faculty of Humanities attended special courses of Summer and Winter Schools organized by Georgian and foreign scientists. At the given schools the students became familiar with the essence of digital Kartvelology comprising: the methodological issues involved in the creation of the corpus, the major principles of annotation, the basic strategies of building up thematic corpora and its management.

Therefore, the involvement of the Georgian students in the creation of "The Georgian National Corpus" acquires the greatest national importance. On the one hand, the students facilitate the preservation of their national language and linguistic heritage, while on the other hand, they get acquainted with the principles of translation from the native language into lingva franca.

Among the innovative courses of the Faculty of Humanities a special attention must be paid to "Abstracting and reviewing of the English text" (ARET). The given course was reconstructed in 2013 and is delivered to the students of the direction of the English Philology. The major importance of $\boldsymbol{A R E T}$ lies in the fact, that it presents the latest principles of translation and transfers the skills of the creation of a valid scientific work. At the end of the course, the best students (having the highest grades) are involved in the project "Parallel corpus of English-Georgian scientific texts". The students are asked to create Georgian translations of the passages of the English scientific texts via using appropriate terminological and phraseological units. In cases of the lack of equivalency, the creation of new Georgian lexical units is facilitated.

The compilation of the "Parallel corpus of English-Georgian scientific texts" acquires the greatest importance in the building of the contemporary Georgian lingual space, because after the completion of the Soviet era, the 
Georgian language regained its state function and started development towards the adaptation to the realities of the contemporary life. A lot of concepts related to history, politics, diplomacy, jurisprudence, market economy and technology entered the Georgian reality. The necessity of their nomination with new Georgian terms has acquired the greatest urgency. Therefore, students' and professionals' works carried out within the framework of parallel corpus directly answer the demands of the modern epoch. All the outcomes of the given corpus will be involved into the large-scale university project "English-Georgian Encyclopedic Dictionary", which will present numerous English terms and their old or newly-created Georgian equivalents comprising almost all field of science. The enrichment of the Georgian language will raise its value, international circulation and competitiveness.

It's worth mentioning, that besides the growing interest towards the creation of the digital parallel corpora, the Georgian scholars pay the greatest attention to the compilation of multi-lingual dictionaries. In 2014-2015 a unique project was carried out at Tbilisi State University. It comprised the creation of five-language dictionary (Georgian-Megrelian-Laz-Svan-English) and was financed by the Embassy of Switzerland and Swiss Cooperation Office in the South Caucasus. The preparation procedure was initiated by Prof. RamazKurdadze and united professors and $\mathrm{PhD}$ student of Tbilisi State University.

After the publication of the dictionary it was assessed as a unique presentation of Kartvelian languages and their English counterparts. 6000 entries shed the light to the contemporary relationship between Kartvelian languages Georgian, Megrelian, Laz, Svan - which make up the South Caucasian language family. The importance of the given multi-lingual dictionary can be assessed from two points of view: a local significance and an international significance.

From the local perspective the Georgian-Megrelian-Laz-Svan-English dictionary:

- "demonstrates the view of the linguistic affinity of the Kartvelian tribes" (Georgian-Megrelian-Laz-Svan-English Dictionary, 2015);

- "manifests the trail of the influence of non-cognate languages (viz. Russian, Greek, Turkish)" (Georgian-Megrelian-Laz-Svan-English Dictionary, 2015);

- maintains national identity via the preservation of the local linguistic diversity.

From the international perspective the Georgian-Megrelian-Laz-SvanEnglish dictionary:

- represents a rare attempt of the presentation of lexical units of the Kartvelian languages and their English counterparts and therefore, 
raises the value, international circulation and competitiveness of all Kartvelian languages;

- popularizes the Kartvelian languages among the English-speaking society of the world;

- $\quad$ serves as a useful tool of foreign Kartvelologists, who are interested in the investigation of the South Caucasian languages.

\section{Conclusions}

All the above mentioned enables us to conclude, that ongoing globalizing processes stipulate significant changes within the educational system of Tbilisi State University, which undergoes important reformation processes. On the one hand, it fosters the implementation of innovative student-oriented methodologies (e-learning, e-portals, involvement in different projects, etc.), while on the other hand, it participates in the building of the nation's conscience directed towards the preservation of the national identity.

"Maintenance of linguistic diversity via the preservation of the national language" - this is the major task of the projects carried out with an active involvement of the students of the Faculty of Humanities at IvaneJavakhishvili Tbilisi State University. The given projects directly answer the demands of European organizations and facilitate Georgia's integration into the European area via sharing western strategies directed towards the defence of national uniqueness.

Therefore, the highlighted methods of student-oriented teaching can serve as an exemplary and useful model of progress for those Post-Soviet universities of the world, which strive to join the European Higher Education Area.

\section{References}

Castello, X., Loureiro-Porto, L., Eguiluz, V. M., \& Miguel, M. S. (2008). The fate of bilingualism in a model of language competition. In: Takahashi, S., Sallach, D., Rouchier, J., (Eds.). Advancing Social Simulation: The First World Congress (pp. 8393). Japan: Springer.

Council of Europe Committee of Ministers.Downloaded from https://wcd.coe.int/com. instranet.InstraServlet?command $=$ com.instranet. CmdBlobGet $\&$ InstranetImage $=601630$ $\&$ SecMode $=1 \&$ DocId $=676400 \&$ Usage $=2$.

Endangered languages. Downloaded from (http://www.unesco.org/new/en/culture/themes/ endangered-languages/biodiversity-and-linguistic-diversity/).

Georgian-Megrelian-Laz-Svan-English Dictionary (2015). Tbilisi: Petiti.

Gill, S. K. (2013). Language policy challenges in multi-ethnic Malaysia. New York: Springer Science \& Business Media. 
Darejan Tvaltvadze, Irina Gvelesiani. Recent Redagogical Strategies Directed Towards the Maintenance of National Identity

Gippert, J., \& Tandashvili, M. (2012). Structuring a Diachronic Corpus. Proceedings of the international conference „Historical Corpora 2012“. Downloaded from http://armazi.uni-frankfurt.de/gnc/gnc_2012.pdf.

Hüsamettin, İ., \& Feyzullah, Ü. (2013). The Construction of National Identity in Modern Times: Theoretical Perspective. International Journal of Humanities and Social Science, 11, 223-232. Downloaded from http://www.ijhssnet.com/journals/ Vol_3_No_11_June_2013/24.pdf.

Minasyan, A. (2014). Language policy, national identity and politics, European Scientific Journal, 2, 273-277.

Tandashvili, M., \& Purtskhvanidze, Z. (2014). Manual of Corpus Linguistics.Frankfurt: Frankfurt University Press.

The Georgian National Corpus. Downloaded from http://gnc.gov.ge/gnc/static/portal/ gnc.html. 